\title{
PHYSICO-CHEMICAL ANALYSIS OF THE NATURAL FOOD COLOURS EXTRACTED BY USING NANO TECHNOLOGY
}

\section{P. SRILATHA, K. UMAMAHESHWARI, BUTTI PRABHAKAR \& K. V. PRAMOD KUMAR}

Department of Post Graduate and Research Center, PJTSAU, Rajendra Nagar, Hyderabad, India

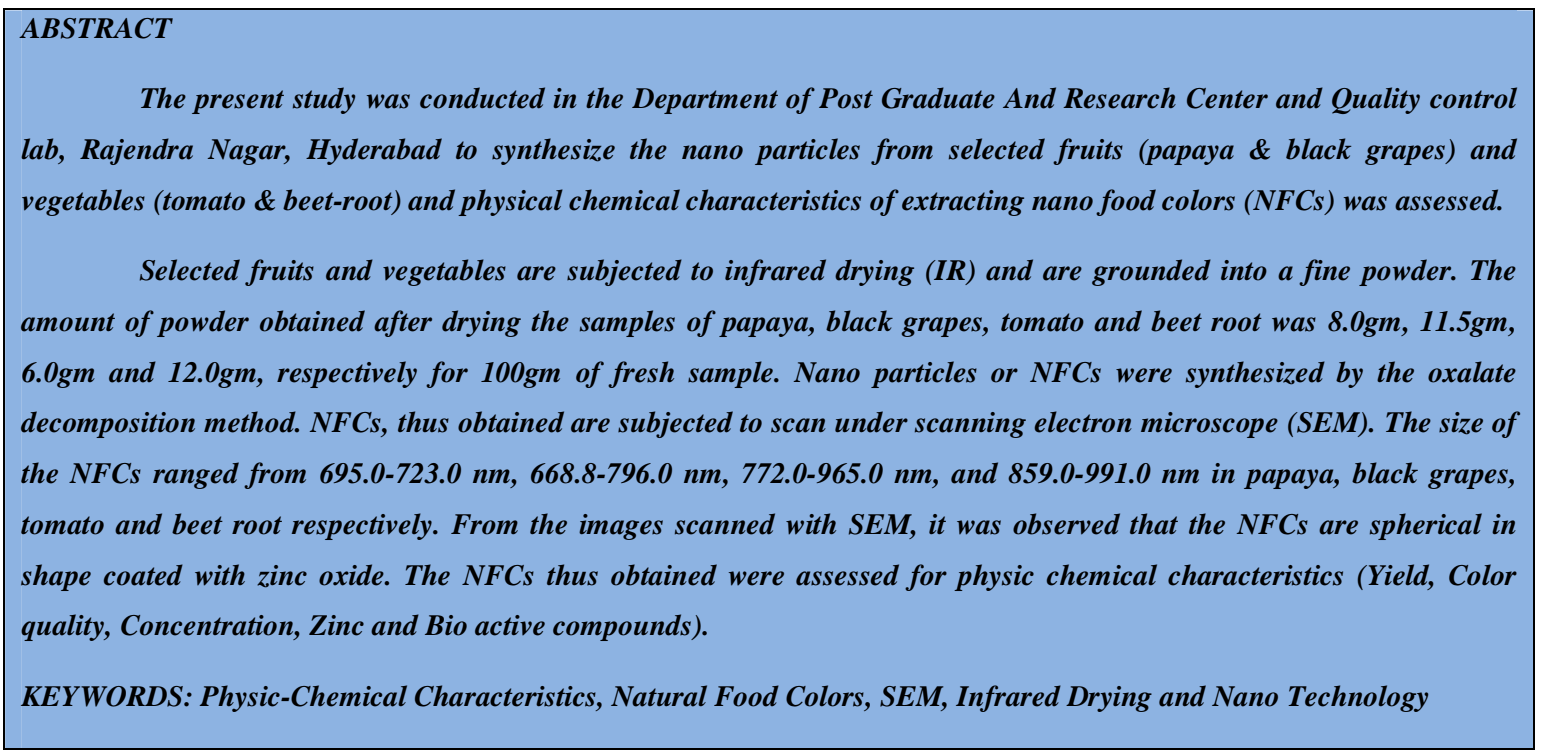

Received: May 08, 2017; Accepted: May 31, 2017; Published: Jun 14, 2017; Paper Id.: IJASRJUN201756

\section{INTRODUCTION}

Color becomes the most sensitive part of any commodity not only for its appeal, but also it enhances consumer acceptability. The demand for natural colors is increasing day by day because of awareness of positive health benefit out of natural compounds (Chattopadhyay et al. 2008). The organic color stuffs are obtained from roots, stems, leaves, barks, flowers and berries of various plants and from certain insects and shellfish. The inorganic pigments are insoluble salts which are precipitated (Paul et al. 1996). There is a worldwide trend towards the use of natural additives and food colorant in food applications (Ghorpade et al. 1995). Nanotechnology describes materials, devices and systems with structures and components exhibiting new and significantly improved physical, chemical and biological properties, as well as the phenomena and processes, enabled by the ability to control properties of nano scale (Miyazaki and Islam, 2007). A range of nano techniques and materials are being developed to control over food character traits (Gardener, 2002). Inorganic nano materials are stable under harsh process conditions, but also generally regarded as safe to human beings and animals (Stoimenov et al. 2002; Fu et al. 2005).

Potential applications of nanotechnology are formulated of food products, food packaging applications and new materials for food equipments, new Sanitizers and also water purification (Enculescu et al. 2008). 


\section{MATERIALS AND METHODS}

\section{Raw Materials}

The fruits (papaya \& black grapes) and vegetables (tomato \& beet root) were procured from local market. Chemicals used in this experimentation and analysis were of food grade, purchased from standard Indian companies.

\section{Preparation}

Fruits (papaya \& black grapes) and vegetables (tomato \& beet-root) of each $1 \mathrm{~kg}$ were thoroughly washed in hot water and were cut into thin pieces. These pieces are placed in separate trays and were subjected to Infrared (IR) drying. After drying, the samples were cooled and grinded in a conventional grinder into fine powder.

\section{Synthesis of Color Nano Particles}

In the present study, NFCs were synthesized using dry powders from selected fruits (papaya \& black grapes) and vegetables (tomato \& beet root) by the oxalate decomposition method. Flow chart for synthesis of nano particles is given in Figure 1

Mix equimolar concentration of zinc source and oxalic acid

Ground into powder and analyze to higher temperature like $600^{\circ} \mathrm{C}$

Powders of fruit and vegetables samples were sieved using 2 um sieve

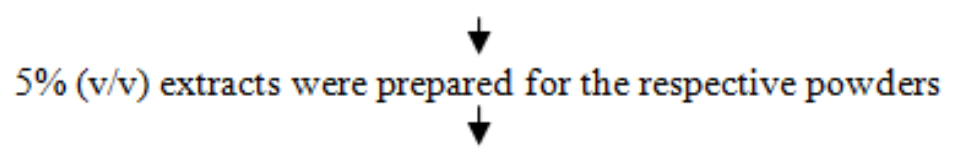

$1 \%$ gum was prepared in $100 \mathrm{ml}$ conical flask

$0.2 \%$ nano scale zinc oxide solution was prepared

$1 \%$ gum solution was added to it while stirring

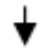

Prepared 5\% extract was added slowly with string and heating

Final solution was made up to $100 \mathrm{ml}$

Solution was kept at room temperature for one hour for stabilization

Figure 1: Flow Chart for Synthesis of Nano Particles 


\section{Physic-Chemical Analysis}

NFCs extracted were subjected to analysis, soon after their extraction for parameters like yield, color quality, concentration, zinc, total carotene, anthocyanin, lycopene and total beta lay contentedly. Yield of color was estimated using weighment method on dry weight basis. The color quality of the samples was estimated by using Hunterlab calorimeter (Color Quest XE hunter Lab, USA). The procedure for estimation of zinc was given by Garcia et.al. 1974. The concentration of the color was estimated by spectrophotometer as given by Jayaraman, 1996. Procedures for estimation of total carotene, anthocyanin, lycopene and total beta lain content were given by Ranganna (1986).

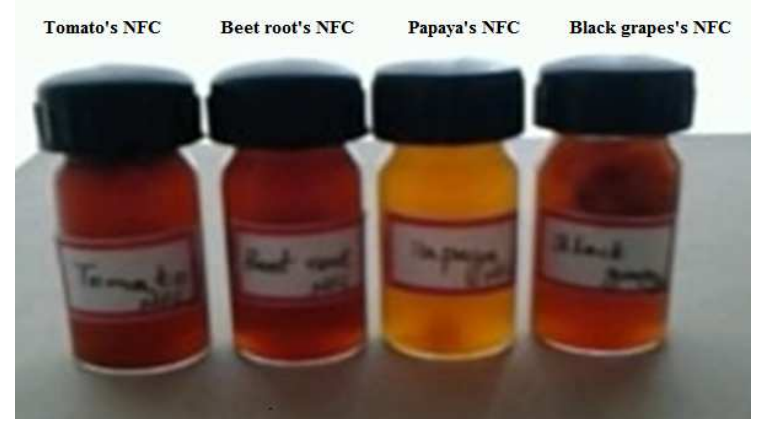

Plate 1: NFCs synthesized from Selected Fruits and Vegetables (Tomato, Beet Root, Papaya and Black Grapes)

\section{Physical Quality Attributes}

\section{Determination of Particle Size}

\section{Scanning Electron Microscope (SEM) Protocol}

Samples were exposed against $2.5 \%$ gluteraldehyde in $0.1 \mathrm{M}$ phosphate buffer ( $\mathrm{pH} 7.2$ ) for 1 hour at room temperature and dehydrated in silica desiccators for 1 hour. The processed samples were mounted over the stubs with double-sided carbon conductivity tape, and a thin layer of gold coat over the samples were done by using an automated sputter coater (Model-JEOL JFC-1600) for 3 minutes, and scanned under Scanning Electron Microscope (SEM - Model: JOEL-JSM 5600) at required magnifications (John and Lonnie, 1998).

\section{FT-IR Measurements}

The FT-IR measurements of the natural color encapsulated nanoparticles were carried out with TENSOR-27 (Bruker). To remove any free biomass residue or compound that is not the capping legend of the nano particles, the residual solution of $100 \mathrm{ml}$ after the reaction was centrifuged at $15000 \mathrm{RPM}$ for $15 \mathrm{~min}$, and the resulting suspension was re-dispersed in $10 \mathrm{ml}$ sterile distilled water. The centrifuging and re dispersing process was repeated three times. Thereafter, the purified suspension was freeze dried to obtain a dried powder. Finally, the dried nano particles were analyzed.

\section{Statistical Analysis}

The data were analyzed for difference of significance by ANOVA used CRD and CD values are presented 


\section{RESULTS AND DISCUSSIONS}

\section{Drying of Samples and Preparation of Fine Powder}

The yield of the powder obtained after drying and grinding of samples is given in table 1

Table 1: Yield of Powder Obtained From the Given Samples after Drying and Grinding

\begin{tabular}{|l|c|l|l|c|}
\hline \multicolumn{1}{|c|}{ Sample } & \multicolumn{1}{|c|}{ Papaya } & \multicolumn{1}{c|}{ Black Grapes } & \multicolumn{1}{c|}{ Tomato } & Beet root \\
\hline $\begin{array}{l}\text { Weight of powder } \\
\text { in (gm)/1kg of fresh sample }\end{array}$ & $80.0(8.0)$ & $115.0(11.5)$ & $60.0(6.0)$ & $120.0(12.0)$ \\
\hline
\end{tabular}

* Figures in parenthesis indicate percentages.

\section{Particle Size and Structure}

\section{SEM}

The NFCs synthesized from selected fruits (papaya \& black grapes) and vegetables (tomato \& beet root) were subjected to scan under Scanning Electron Microscope (SEM). The plates pertaining to the size and structure of the NFCs synthesized from selected fruits (papaya \& black grapes) and vegetables (tomato \& beet root) scanned with SEM are given in plate no's 4.1, 4.2, 4.3 \& 4.4 for papaya, black grapes, tomato and beet-root, respectively. From the images scanned with a scanning electron microscope, it was found that the nano particles are spherical and agglomeralated in nature. They are found intact with the coating material (Zno). The coating material is highly thick holding the nano particles inside. It was also observed that the size of the color particles was in nanometers, where as the size of the coating material was in micrometers which showed that the zinc oxide was highly coated around the nano particles.

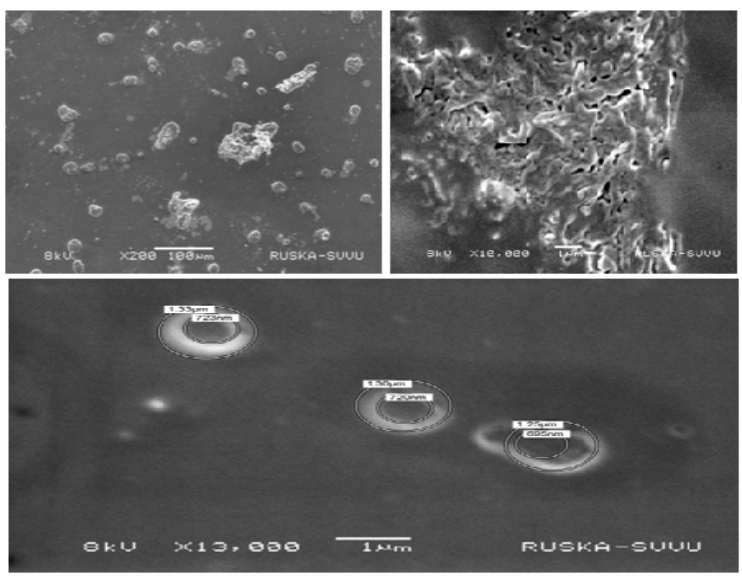

Plate 4.1: Size and structure of papaya's NFC

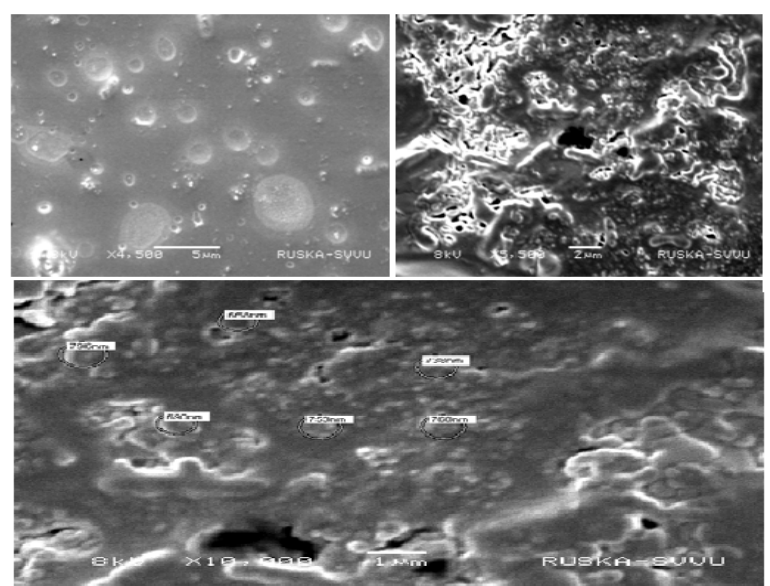

Plate 4.2 Size and structure of black grape's NFC 


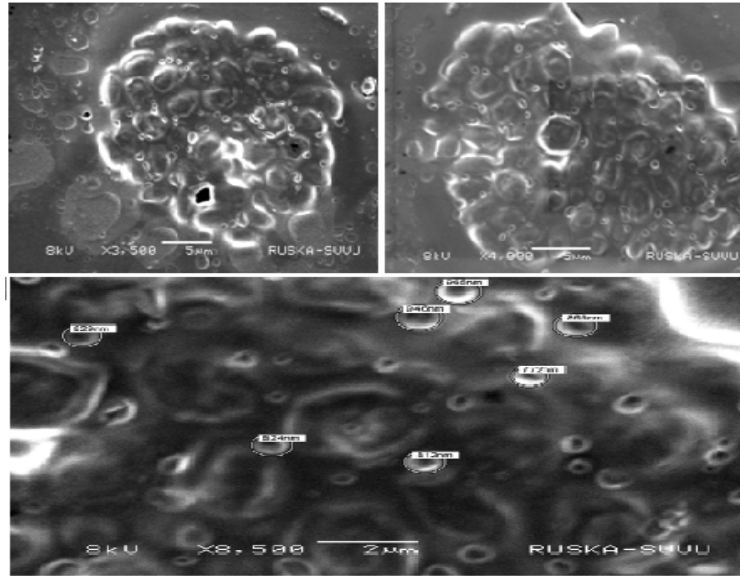

Plate 4.3: Size and Structure of Tomato's NFC

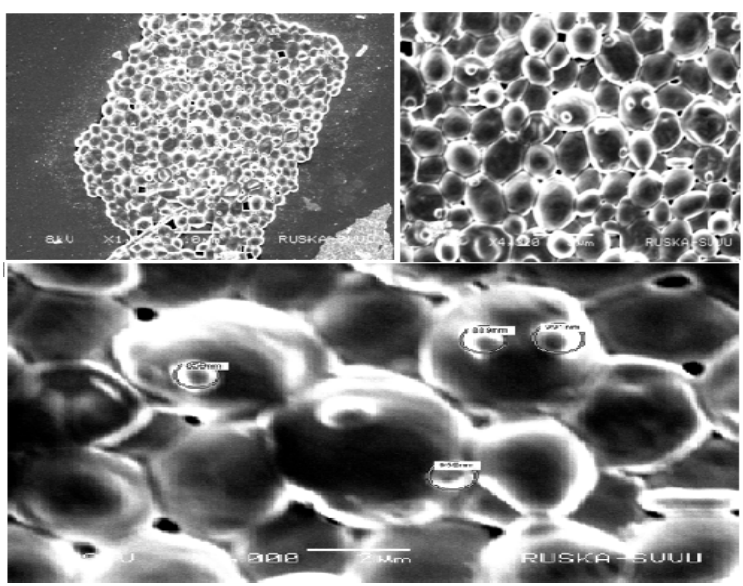

Plate 4.4 Size and Structure of Beet Root's NFC

The Size of the NFCs Obtained is given in Table 2.

Table 2: Size of NFCs Obtained from the Selected Fruits (Papaya \& Black Grapes) \& Vegetables (Tomato \& Beet Root)

\begin{tabular}{|l|c|c|}
\hline Sample & Range(nm) & Average (nm) \\
\hline Papaya & $695.0-723.0$ & 713.0 \\
\hline Black grapes & $668.0-796.0$ & 736.0 \\
\hline Tomato & $772.0-965.0$ & 859.0 \\
\hline Beet root & $859.0-991.0$ & 925.0 \\
\hline
\end{tabular}

The results in the above table indicated that the size of the NFCs varied from sample to sample. The size of the NFCs synthesized from papaya ranged from 695.0-723.0 nm, from black grapes (668.0-796.0 nm), from tomato (772.0$965.0 \mathrm{~nm}$ ) and from beet root it ranged from 859.0-991.0 $\mathrm{nm}$. The average size of the particles was 713.0, 736.0, 859.0 and $925.0 \mathrm{~mm}$ in papaya, black grapes, tomato and beet-root, respectively.

\section{FT-IR Measurements}

FT-IR results revealed that the absorption bands were present at $3349,1635 \mathrm{~cm}^{-1}$ in NFCs of grape, tomato and papaya. The absorption band at $3349 \mathrm{~cm}^{-1}$ is assigned to the $\mathrm{N}-\mathrm{H}$ group or primary amides which are present in the respective color extract. This also indicates the presence of alcohols with free $\mathrm{OH}$. The absorption band $1635 \mathrm{~cm}^{-1}$ corresponds to the presence of nitrites and tertiary amides. Whereas, the absorption band $2102 \mathrm{~cm}^{-1}$, which is present in the sample Beet root NFC is assigned to the aromatic isonitriles, which is absent in the other samples tested. The results indicated that the color of the respective extract was clearly encapsulated by the zinc nano particles. According to Cross, 1960 for Tran's fatty acid absorption bands were present at $1000-950 \mathrm{~cm}^{-1}$ and for this fatty acid at $780-680 \mathrm{~cm}^{-1}$.
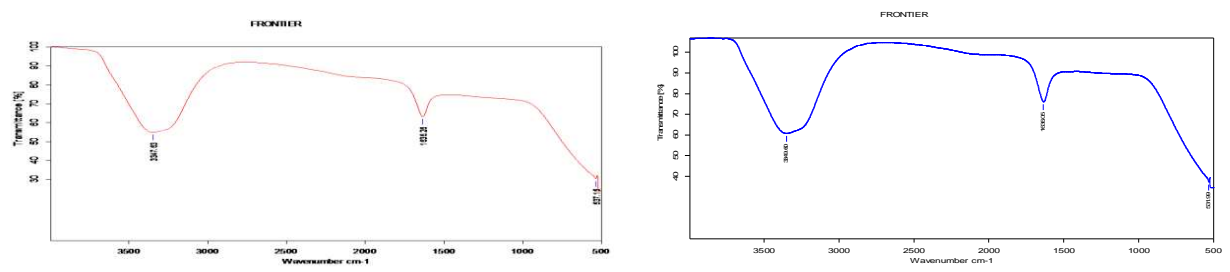

Figure 4.1: FT-IR Spectrum of Papaya's NFC Figure 4.2: FT-IR Spectrum of Black Grapes's NFC 

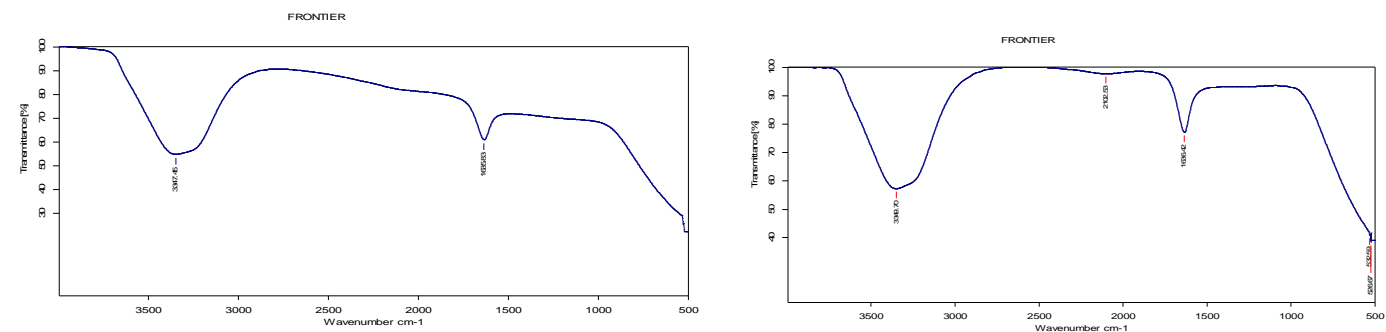

Figure 4.3: FT-IR spectrum of Tomato' NFC Figure 4.4: FT-IR spectrum of Beet root's NFC

\section{DLS and Zeta Potential Measurements}

The particle size (DLS) and zeta potential measurements of the prepared samples were carried out using Nano particles, SZ-100 (HORIBA). The hydrodynamic radius of the color encapsulated nano particles was recorded as $123 \mathrm{~nm}$, 232nm, 385nm; 1005nm corresponds to Papaya, Tomato, Grapes and Beet root, respectively. The sizes (hydrodynamic radius) of NFCs synthesized are in good correlation with the sizes measured under SEM. The higher zeta potential values (Grape: $-40.5 \mathrm{mV}$, Tomato: $-36.5 \mathrm{mV}$, Papaya: $-32.7 \mathrm{mV}$ and Beetroot: $-41 \mathrm{mV}$ ) for all the samples tested indicate the high stability of the formed particles.

\section{Yield}

The yield of NFCs synthesized from selected fruits (papaya \& black grapes) and vegetables (tomato \& beet root) was calculated and recorded in the table 3 .

Table 3: Yield of Nfes Synthesized From Selected Fruits (Papaya \& Black Grapes) and Vegetables (Tomato \& Beet Root)

\begin{tabular}{|l|c|c|c|}
\hline Sample & $\begin{array}{l}\text { Weight of the Fresh } \\
\text { Sample(Gm) }\end{array}$ & $\begin{array}{l}\text { Weight of the } \\
\text { Dry Powder }(\mathbf{G m})\end{array}$ & $\begin{array}{l}\text { Volume of Nano } \\
\text { Particle Solution(MI) }\end{array}$ \\
\hline Papaya & 100.0 & 8.0 & 160.0 \\
\hline Black grapes & 100.0 & 11.5 & 230.0 \\
\hline Tomato & 100.0 & 6.0 & 120.0 \\
\hline Beet root & 100.0 & 12.0 & 240.0 \\
\hline
\end{tabular}

The results illustrated in the table 3 indicated that the yield of the nano particle solution was $160.0 \mathrm{ml}$ of $8.0 \mathrm{mg}$ of dry powder of papaya, $230.0 \mathrm{ml}$ of $11.5 \mathrm{mg}$ of black grapes, $120.0 \mathrm{ml}$ of $6.0 \mathrm{mg}$ of tomato and $240.0 \mathrm{ml}$ of $12 \mathrm{mg}$ of beetroot for $100 \mathrm{mg}$ of fresh sample.

\section{Concentration}

The results obtained for concentration of NFCs from selected fruits (papaya \& black grapes) and vegetables (tomato \& beet root) is given in the table 4.

Table 4: Concentration of Nfcs from Selected Fruits (Papaya \&
Black Grapes) and Vegetables (Tomato \& Beet Root)
\begin{tabular}{|l|c|c|c|c|}
\hline Sample & Papaya & Black grapes & Tomato & Beet root \\
\hline Concentration & 4.38 & 6.67 & 3.39 & 7.10 \\
\hline
\end{tabular}

In beet root, the concentration of color was found to be higher (7.10), followed by black grapes (6.67), papaya (4.38) and least was for tomato (3.39). Between the vegetable samples the concentration of color was found to be higher in the Beetroot (7.10) and lower in tomato (3.39). In fruit samples the concentration of color was found to be higher in black 
grapes (6.67) followed by papaya (4.38). The values obtained in the present study for concentration are much higher compared to the value reported by Priya mandhana et al, (2007). This may be mainly due to the synthesis of the color nano particles with very small size and large surface area to volume ratio.

\section{Color Quality}

The color quality of NFCs synthesized from selected fruits (papaya \& black grapes) and vegetables (tomato \& beet root) is given in table 5 . Table 5: Color Quality of Nfes Synthesized From Selected Fruits (Papaya
\& Black Grapes) and Vegetables (Tomato \& Beet Root)

\begin{tabular}{|l|c|c|c|}
\hline \multicolumn{1}{|c|}{ Sample } & Light (L) & Hue (a) & Brightness (b) \\
\hline Papaya & 14.55 & 3.33 & 4.59 \\
\hline Black grapes & 16.56 & 3.59 & 8.53 \\
\hline Tomato & 14.26 & 2.73 & 5.45 \\
\hline Beet root & 13.36 & 4.56 & 5.34 \\
\hline
\end{tabular}

The color value was mainly determined in the form of light, hue and brightness. Among the vegetable samples, lightness was found to be higher for NFC with tomato (14.26\%) followed by NFC with beet root (13.36\%). In the fruit samples lightness was found to be higher in NFC with black grapes (16.56\%) and lower in the NFC with papaya (14.55\%). The values for lightness for all the NFCs were extended nearly towards ' 0 ' value, i.e., black indicating good color quality. The + a (Hue) value which indicates more of redness and less of greenness was higher for Beetroot NFC (4.56\%) compared to the NFC with tomato $(2.73 \%)$ among vegetable samples. In fruit samples hue, value was higher for NFC with black grapes $(3.59 \%)$ compared to the NFC with papaya $(3.33 \%)$. Between the vegetable samples the brightness was found to be higher for NFC with tomato (5.45\%) and lower for NFC with beet root (5.34\%) and in fruit samples higher for NFC with black grapes $(8.53 \%)$ compared to the NFC with papaya (4.59\%).

Zinc

The nano particles synthesized from selected fruits (papaya \& black grapes) and vegetables (tomato \& beet root) in the present study are coated with zinc oxide. Hence, zinc was estimated in the NFCs to know the amount of zinc that is present in the given nano particle solution. As zinc rich foods tend to be expensive, the daily intakes of zinc were much lesser to the requirement. The recommended daily intake of zinc is $15 \mathrm{mg} / \mathrm{day}$. The amount of zinc in the given NFCs of selected fruits (papaya \& black grapes) and vegetables (tomato \& beet root) is given in the table 6.

Table 6: Zinc Content in the Nfcs Synthesized From Selected Fruits (Papaya \& Black Grapes)And Vegetables (Tomato \& Beet Root)

\begin{tabular}{|c|c|c|c|c|}
\hline Sample & Papaya & Black Grapes & Tomato & Beet Root \\
\hline Zinc content(mg/100gm) & 3.94 & 6.81 & 2.95 & 7.51 \\
\hline
\end{tabular}

The results illustrated in the table 6 indicated that the zinc content in NFCs synthesized from papaya was 3.94 $\mathrm{mg} / 100 \mathrm{gm}, 6.81 \mathrm{mg}$ in black grapes, $2.95 \mathrm{mg}$ in tomato and $7.51 \mathrm{mg} / 100 \mathrm{gm}$ in beet root. In fresh samples of tomato and beet root, the zinc content was 0.41 and 0.91, respectively, whereas in papaya and black grapes, it was not reported (Gopalan et al. 2007). When compared to the above values, it was observed that, the Zinc content of NFCs synthesized was higher, indicating the significance of NFCs in enhancing the Zinc content of the food products. Zinc and zinc oxide were used as nutritional additives and antimicrobial agents in food packaging (Brunner, 2006). Hence, these NFCs also can be used as nutritional additives and also as antimicrobial agents. 


\section{Bioactive Compounds}

The quantity of bio active compounds was estimated in the NFCs synthesized from selected fruits such as total carotenes (papaya) \& anthocyanins (black grapes) and vegetables such as lycopene (tomato) \& battalions (beet root) and results are given in table 7 .

Table 7: Quantity of Bio Active Compounds in Nfcs Synthesized from Selected Fruits (Papaya \& Black Grapes) and Vegetables (Tomato \& Beet Root)

\begin{tabular}{|l|c|c|}
\hline \multicolumn{1}{|c|}{ Bioactive Compounds } & O.D Value & Content In (100gm) \\
\hline Total carotenes (papaya) & 0.31 & $92.16 \mu \mathrm{g}$ \\
\hline Anthocyanins (black grapes) & 0.27 & $118.91 \mathrm{mg}$ \\
\hline Lycopene (tomato) & 0.125 & $4.68 \mathrm{mg}$ \\
\hline Betalains (beet root) & 2.2 & $5.28 \mathrm{mg}$ \\
\hline
\end{tabular}

Results in the table 7 indicates that the total carotene content in the NFC with papaya was $92.16 \mu \mathrm{g} / 100 \mathrm{gms}$. The anthocyanin content in NFC with black grapes was $118.91 \mathrm{mg} / 100 \mathrm{gm}$. The lycopene content in the NFC with tomato was $4.68 \mathrm{mg}$ and betalain content in the NFC with beet root was $5.28 \mathrm{mg} / 100 \mathrm{gm}$.

\section{CONCLUSIONS}

Thus, it can be concluded that it is feasible to synthesize NFCs from dehydrated powders of selected fruits (papaya and black grapes) and vegetables (tomato and beet root) with good physic-chemical (yield, color quality, concentration, zinc and bio active compounds) properties.

\section{REFERENCES}

1. Brunner, T., Piusmanser, P., Spohn, P., Grass, R., Limbach, L., Ruinink, A.B and Stark, W.2006. In Vitro

2. Cytotoxicity of Oxide Nano particles: Comparison to Asbestos, Silica, and the Effect of Particle Solubility. Environmental Science and Technology. 40:4374-4381.

3. Chattopadhyay Pritam., Sandi pan Chattered and Sukanta K. Sen. 2008. Biotechnological potential of natural food

4. grade bio colorants. African Journal of Biotechnology: 7 (17). 2972-2985.

5. Enculescu, I., Matei, E., Sima, M., Neumann, R., Granville, S., Ansermet, J.P. 2008. Preparation and Properties of

6. Cobalt Doped ZnO Nanowires. IEEE Transactions on Magnetics. 44 911): 2678-2680, ISSN 0018-9464.

7. Gardener, E. 2002. “Brainy Food: Academia, Industry Sink Their Teeth Into Edible Nano.” Small Times. June 21.

8. Ghorpade, V. M., Deshpande, S. S and Salunkhe, D. K. 1995. Food colors in Food additive toxicology. J. Maga and T. Anthony (Eds). Marcel Dekker. New York: 179-233.

9. Gopalan, C., Rama Sastri, B. V and Balasubramanian, S. C. 2007. Nutritive value of Indian Foods. National Institute of Nutrition. Indian Council of Medical Research, Hyderabad: 68-73.

10. John, J. Bozzola and Lonnie, D. Russell. 1998. Electron Microscopy Principles and Techniques for Biologists $2^{\text {nd }}$ edition. Jones and Bartlett Publishers, Sudbury, Massachusetts.19-24, 54-55 and 63-67.

11. Miyazaki, K, Islam, N. 2007. Nanotechnology systems of innovation - An analysis of industry and academia research activities. Technovation. 27: 661-671. 
12. Paul, R., Malanker, J. V and Naik, S. R. 1996. Textile dyer and printer. 23(10): 16.

13. Priya Mandhana and Uma maheswari, K. 2007. Extraction, stability and utilization of bio food colors from pumpkin(cucurbits maxima) and prickly pear (Opuntia lasiacantha), M.Sc thesis Acharya N.G. Ranga Agricultural University.

14. Ranganna, S.1986. Handbook of Analysis and Quality Control for Fruit and Vegetable Products, 2nd ed. Tata

15. McGraw-Hill, New Delhi, India.

16. Stoimenov, P.K., Klinger, R.L., Marchin, G.L and Klabunde, K.J. 2002. Metal oxide nano particles as bactericidal agents. Langmuir. 18: 6679-6686. 
